\title{
Efficient conversion of glycerol into high value-added chemicals by partial oxidation
}

\author{
Tsutomu Chida ${ }^{1}$, Kousuke Hiromori ${ }^{1}$, Naomi Shibasaki-Kitakawa ${ }^{1}$, Naoki Mimura ${ }^{2}$, \\ Aritomo Yamaguchi², and Atsushi Takahashi ${ }^{2}$ \\ ${ }^{1}$ Tohoku University \\ ${ }^{2}$ Affiliation not available
}

May 12, 2020

\begin{abstract}
Glycerol can be effectively converted to glyceric acid, a high value-added pharmaceutical raw material, through its partial oxidation over an Au catalyst under strongly basic conditions. The factors important for the highly selective production of glyceric acid were investigated experimentally. It was clarified that $\mathrm{NaOH}$ was involved in the glycerol activation step to a glycerol alkoxide intermediate in the liquid phase, then glyceric acid was formed by $\mathrm{OOH}$ species derived from $\mathrm{O}_{2}$ on an $\mathrm{Au}$ catalyst in the partial oxidation step. We have newly discovered the concerted effect of $\mathrm{NaOH}$ and $\mathrm{O}_{2}$ in different reaction steps.
\end{abstract}

\section{Hosted file}

JAOCS_MS.doc available at https://authorea.com/users/321282/articles/450566-efficientconversion-of-glycerol-into-high-value-added-chemicals-by-partial-oxidation 